Herbert Bruch · Faszination und Abwehr 


\section{Herbert Bruch}

\section{Faszination und Abwehr}

Histonisch-psychologische Studien zu Eduard Mörikes Roman „Maler Nolten"

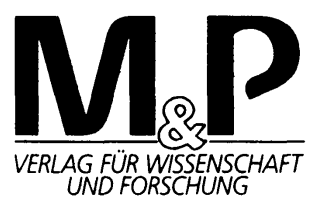


Die Deutsche Bibliothek - CIP-Einheitsaufnahme

\section{Bruch, Herbert:}

Faszination und Abwehr : historisch-psychologische Studien zu

Eduard Mörikes Roman "Maler Nolten" / Herbert Bruch. -

Stuttgart : $M$ und P, Verl. für Wiss. und Forschung, 1992

Zugl.: München, Univ., Diss., 1991

ISBN 978-3-476-45017-3

\section{ISBN 978-3-476-45017-3}

ISBN 978-3-476-04175-3 (eBook)

DOI 10.1007/978-3-476-04175-3

Dieses Werk ist einschließlich aller seiner Teile geschützt. Jede Verwertung außerhalb der engen Grenzen des Urheberrechtsgesetzes ist ohne Zustimmung des Verlages unzulässig und strafbar., Das gilt insbesondere für Vervielfältigungen, Übersetzungen, Mikroverfilmungen und Einspeichenung in elektronischen Systemen.

M\&P Verlag für Wissenschaft und Forschung ein Verlag der J. B.Metzlerschen Verlagsbuchhandlung und Carl Emst Poeschel Verlag GmbH in Stuttgart

(c) 1992 Springer-Verlag GmbH Deutschland Ursprünglich erschienen bei J. B. Metzlersche Verlagsbuchhandlung und Carl Ernst Poeschel Verlag GmbH in Stuttgart 1992 


\section{Vorwort}

Die vorliegenden Mörike-Studien wurden im Sommersemester 1991 von der Philosophischen Fakultät der Ludwig-Maximilians-Universität München als Dissertation angenommen. Für den Druck wurden sie leicht überarbeitet.

Was nun als Ganzes erscheinen will, hätte ohne die Anteilnahme derer, die den oft verschlungenen Entstehungsprozeß dieses Buches begleitet haben, schwerlich einen sinnvollen Abschluß gefunden. $\mathrm{Zu}$ danken habe ich vor allem meiner Lehrerin Renate von Heydebrand, die, an der MörikeForschung maßgebend beteiligt, das Projekt mit engagierter Kritik und geduldiger Neugier betreut hat. Ich danke ferner meinen Freunden Harald Eggebrecht, auf den die erste Anregung zur Beschäftigung mit Mörike zurückgeht, und Peter Strohschneider, der mir in vielen Diskussionen die Gelegenheit gab, Schwerverständliches zu klären und Selbstzweifel zu überwinden.

München, im August 1992

Herbert Bruch 


\section{Inhaltsverzeichnis}

Vorwort

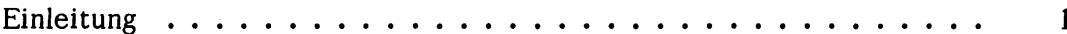

ERSTES KAPITEL

Das Spiel mit dem Feuer: Der Feuerreiter . . . . . . . . . 5

1. Perspektiven der Forschung und eigener Ansatz . . . . . . . . 6

Formanalyse (1) 7 - Der Prosavorspann zum Gedicht 9 - Motivische Einbindung der Ballade in den Roman 18 - Vergleich mit "Erinnerung" 19 - Vergleich mit der "Bekehrung" Jung Volkers 27

2. Die politische Konnotation ................

Formanalyse (2) 29 - Psychologische Deutung der Form 33 - Metaphern, die auf Revolution deuten 34 - Vergleich mit "Der Abgebrannte" 35 - Weitere Revolutionsmetaphern 36 - Zwischenbilanz anhand von Tiecks Revolutionssatire "Die verkehrte Welt" 42 - Nochmals Revolutionsmetaphern 43 - Vergleich mit dem Spillner-Fragment 56 - Mörikes politischer Standort 59 - Napoleon 60 - Mörikes Einstellung zur März-Revolution 66 - Körperliche Bewegungsfreiheit und revolutionäre Freiheitsbewegung 68

3. Exkurs: Revolution und Sexualität

Liebe als kryptopolitische Kategorie ............

Beispiele für die Korrelation von Sexualität und Revolution in der zeitgenössischen Literatur 71 - Versuch einer sozialpsychologischen Deutung, orientiert an Sigmund Freud 78 - und Norbert Elias 80

4. Die erotische Konnotation $\ldots \ldots \ldots \ldots \ldots \ldots$

Vergleich mit "Lucie Gelmeroth" 89 - "Der Gärtner" 90 - "Die schlimme Greth und der Königssohn" (1) 93 - "Begegnung" 95 "Die schlimme Greth" (2) 95 - Peregrina 99 - "Liebesvorzeichen" 100 - Mentalitätsgeschichtlicher Hintergrund 104 - Biographischer Hintergrund 105 - Thesen zum Verhältnis von angst- und lustbetonter Erotik in Mörikes Dichtung 110

\section{ZWEITES KAPITEL}

Allmacht und Ohnmacht: Jung Volker. Erste Annäherung an das psychodramatische Substrat des Maler Nolten .........

1. Verknüpfung der Jung-Volker-Texte mit dem Roman Textanalytische Einführung

Das Echogedicht "Frau Adelheid" 117 - Agnes' mühsamer Aufstieg zum Berg Geigenspiel 118 - Das Festzelt des Amandus 119 Geigenspiel und Rehstock 121 - Der Rezeptionshinweis des Amandus 123 - Volkstümlichkeit wird nur suggeriert 123 
2. Die Erzählung des Obristen $\ldots \ldots \ldots \ldots \ldots \ldots$

Antikisierende und poetologische Elemente 127 - Künstler und Rebell 131 - Psychoanalytische Deutung der Grandiosität Jung Volkers 138 - Sinnliche Liebe und "Freiheit" als Gegensätze 141

3. Die Legende von Jung Volkers Jagd und Bekehrung

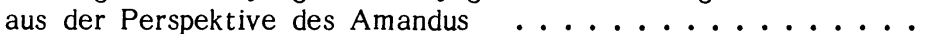

Zerstörung narzißtischer Allmachts-Phantasien durch die Macht des Triebes 143 - Bekehrung zur christlichen Kunst? 147

4. Jung Volkers Jagd und "wunderliche Bekehrung" aus seiner eigenen Sicht

Inzestuöse Züge des Angriffs auf das "eigenthumb der muetter Gottes" 150 - Funktion und sozialhistorischer Hintergrund der Anverwandlung katholischer Glaubensinhalte 152 - Selbststilisierung Jung Volkers als leidender Christus 158

5. Exkurs zu Größe und Kleinheit des Genies ...........

Vergleich mit dem "Märchen vom sichern Mann" 160 - Mörikes Stellungnahme zum Briefwechsel $z$ wischen Goethe und Schiller 162 - Selbstbewußte Genialität ("An einem Wintermorgen") 164 - Gebrochene Grandiosität ("In der Char-Woche") 165

6. Die beiden "Sagen" . . . . . . . . . . . . . .

7. Die beiden abschließenden Lieder .............

Die beiden Mütter Jung Volkers 172 - Komplementäre Einheit der 'guten' und der 'gefährlichen' Mutter 175 - Stilisierung Jung Volkers als Anti-Christ ("Jung Volker, das ist der Räuberhauptmann") 182 - Raymund, der Sänger des letzten Liedes 183

8. Das Geheimnis ....................

\section{DRITTES KAPITEL}

Kunst oder Leben: Orplid und sein Schöpfer Larkens

1. Zum Stand der Forschung ...............

2. Larkens' Prolog . . . . . . . . . . . . . . . . . . 201

3. Das Auge im Auge. Zur Topographie der Insel Orplid . . . . . 205

Selbstreferentialität des Textes 209 - Integration des Schattenspiels in den Roman 211

4. Das Buch im Buch ..................

a) Buch und Baum: Das "dunkle Buch" und das letzte Buch der Bibel 213 - Die "schwarze Weide" und ihre Beziehung zum ersten Buch der Bibel 216 - Orplid als Peregrina-Dichtung 220 - Das Buch als Spiegel des Lesers 224

b) Der eingeweihte Leser: Der "alte Götterspruch" 228 - Voraussetzung für das Verständnis hermetischer Literatur 231

c) Die Uneingeweihten: Kollmer 232 - Die "neuen Leute" 233 Herr Harry 234 - Der Buchdrucker 234 - Wispel 235 
5. Larkens: Schreiben als Selbsttherapie eines Zerrissenen . . . . .

Larkens' psychische Disposition 239 - Daraus resultierende poetische Intention 242 - Rückschlüsse auf "Orplid" 243 - Hypochondrie als "Krankheit zum Tode" 245 - Rückschlüsse auf "Orplid" 247

6. Das psychodramatische Substrat .............

a) Thereile. Die Handlung des Dramoletts verstanden als intrapsychisches Geschehen und Strategie der Konfliktbewältigung 248 - Thereile und Almissa 253 - Drei Argumente gegen eine moralisierende Lesart "Orplids": "das Pathologische der Sache" 257 - Sinnlichkeit der poetischen Sprache 258 - Entleerung der Utopie 260

b) Weyla. Verlagerung des transzendenten Bezugs ins Subjekt 264 - Die Lichtgestalt Weyla und das Licht in Larkens' "magischer Laterne" 268 - intertextuelle Bezüge zur zeitgenössischen Philosophie 270 - Weyla als Muttergottheit 275 - Korrelation des geschichtsphilosophischen Entwurfs mit dem psychodramatischen Substrat 276 - Die Neue Mythologie als heilsame Demütigung des narzißtischen Subjekts? 279 - "Orplid" und Ovid 283 - Grundsätzliche Unaufhebbarkeit der "Leidenschaften" 288 - Funktion des Rückgriffs auf den antiken Mythos 290

\section{VIERTES KAPITEL}

Vaterfiguren im Maler Nolten ..............

1. Maler Tillsen und die beiden zu Beginn des Romans beschriebenen Bilder "doppelten Ursprungs" . . . . . . . . .

Identität als Ziel 300 - "nächtliche Versammlung musikliebender Gespenster" 302 - Antike Form ermöglicht die Überwindung psychischer Widerstände und die Freisetzung 'romantischer' Inhalte 304 - Wassernymphe, Knabe und Satyr 307 - Die Nymphen in der griechischen Mythologie 308 - Nymphios und Nympholeptos 312 - Faktische Schwäche des 'starken Vaters' durch dessen Abhängigkeit von der Mutter 317

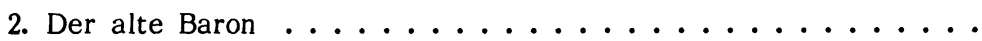

Zeitliche Kontinuität als "Versicherung für unser eignes Daseyn" 320 - Der Tod des alten Barons als Traditionsbruch 321 - Gefühlssicherheit der älteren Generation? 322

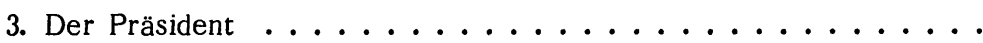

Die "Magie" des Präsidenten ist derjenigen Elisabeths nicht gewachsen 323 - Das Schloß des Präsidenten: 'Verlust der Mitte' 324 - Eine weitere "Baukuriosität" 325

4. Der Förster von Neuburg . . . . . . . . . . . . .

Das "sentimentalische" Naturgefühl des Försters 328 - Demonstration der Fragwürdigkeit des Korrespondenz-Konzepts an Constanze 330 - am Gewitter im Schloßgarten des Präsidenten - 331 an der Beeinflussung Agnes' durch Elisabeth 332 
5. Der Pfarrer von Wolfsbühl . . . . . . . . . . .

Zerstörung legitimer Autorität durch autoritäres Verhalten 334 - Zerrissenheit auch des Philisters 337 - Verlust der christlichen Heilsgewißheit 338

6. Friedrich Nolten ...................

Larkens' Interpretationsanweisung 340 - Empirische Motivation des Wiederholungszwangs durch Blutsverwandtschaft? 341 - Die Reise nach Böhmen: in der Fremde begegnet Friedrich dem entfremdeten Eigenen 342 - Der abwesende Künstlervater 344 - $\mathrm{Zu}$ sammenfassung des Überblicks über Theobalds Väter 345

\section{FÜNFTES KAPITEL}

Theobald Noltens 'romantische' Disposition . . . . . . . . . .

1. Das Neuburger Gespräch . . . . . . . . . . . . .

Ähnlichkeit der Kunstauffassung Theobalds und Larkens' 350 Theobalds kindliche Version Orplids 352 - Agnes' Prädisposition zur Geisteskrankheit: das Analogon zur narzißtischen Disposition des 'romantischen' Künstlers 353 - Vischers Thesen von der "Überwindung der Romantik" und der "doppelten Motivierung" 356 - Mörikes Romantik-Verständnis 358 - Die "natürliche" und die "mystische" Motivierung als zwei einander ergänzende Formen literarischer Psychologie 361 - Psychologie mit Akzent auf dem Logos, demonstriert an Agnes 362 - demonstriert an Constanze 363 - Die mystisch-romantische Motivierung als Einkleidung einer 'modernen' Psychologie des Unbewußten 364

2. Loskine und Elisabeth . . . . . . . . . . . . . . . .

Literarische Präformation des 'Peregrina-Erlebnisses' 366 - Die Begegnung Theobalds und Elisabeths auf dem Rehstock 368 Theobalds Versuch, dem Unbegreiflichen durch "Nachdenken" beizukommen 370 - Platons Wiedererinnerungslehre 371 - Ihre Funktion 372 - Elisabeths magisch-magnetische Geste: kein Rapport 373 - Das 'mystische' Erlebnis: eine Projektion 374 - Das "Bündni $\beta^{\prime \prime}$ Theobalds und Elisabeths beruht auf einem Mißverständnis 374 - Geschwisterliebe 375 - Vergleich mit dem Sonett "An die Geliebte" 378 - Agnes $z$ wischen $z$ wei Spiegeln 380

3. Projektionen und Gegenprojektionen . . . . . . . . . . .

a) Agnes - Theobald 381

b) Theobald - Agnes 384

c) Theobald - Constanze 386

d) Larkens als "Meister" und "Mentor" Theobalds 393 - Kerkerhaft als reziprokes Analogon zur Hermetik "Orplids" 394 - 'Schicksalhafte' Determiniertheit des Willens? 397 - Larkens' "Maskencorrespondenz" mit Agnes 398

Schlußbemerkung .................... 40

Literaturverzeichnis . . . . . . . . . . . . . . . . 409 